\title{
A STUDY OF ENTHESITIS IN SPONDYLOARTHROPATHY IN PATIENTS FROM A TERTIARY CARE SERVICE HOSPITAL
}

\author{
Surajit Ghatak ${ }^{1}$ K. Shanmuganandan ${ }^{2}$
}

\section{HOW TO CITE THIS ARTICLE:}

Surajit Ghatak, K. Shanmuganandan. "A Study of Enthesitis in Spondyloarthropathy in Patients from a Tertiary Care Service Hospital". Journal of Evolution of Medical and Dental Sciences 2014; Vol. 3, Issue 28, July 14; Page: 7822-7830, DOI: $10.14260 /$ jemds/2014/2979

\begin{abstract}
INTRODUCTION: The enthesis is defined as the site of insertion of a tendon, ligament, joint capsule, or fascia to bone. A variety of anatomical sites can be symptomatically affected in Spondyloarthropathy. The spectrum of Spondyloarthropathy consists of Primary Ankylosing spondylitis, Reiter's syndrome/ reactive arthritis, Psoriatic arthropathy and arthropathy associated with Inflammatory Bowel Disease. One of the pathologic hallmarks of the disease is entheseal involvement with insertional tendonitis at different locations. AIM: To study the distribution of involved enthesis in patients with spondyloarthropathy. MATERIAL AND METHODS: The study group included 54 patients from diverse age groups and from different geographic areas in India and was carried out in a tertiary care service hospital. All these patients had historical evidence of sacroiliitis in the form of Inflammatory Back Pain and were diagnosed as Spondyloarthropathy according to ESSG criteria. RESULT: The male to female ratio in this study is 8.2:1. The distribution of enthesitis in our study showed a maximum incidence of heel and costosternal joint. The other enthesis involved were greater trochanter, anterior superior iliac spine and ischial tuberosity. MRI was compared against Plain radiography of Sacroiliac joints for detecting sacroiliitis changes. CONCLUSION: The disease expression has been considered different in males and females. The males with Ankylosing spondylitis have more often had radiological spinal changes and hip involvement than their female counterparts. MRI was compared against Plain radiography of Sacroiliac joints for detecting sacroiliitis changes. MRI was found to be better as compared to Plain radiography in detecting early sacroiliitis with a $\mathrm{P}$ value $<0.05$.
\end{abstract}

KEYWORDS: Enthesitis; Spondyloarthropathy.

INTRODUCTION: The enthesis is defined as the site of insertion of a tendon, ligament, joint capsule, or fascia to bone. A variety of anatomical sites can be symptomatically affected in enthesopathy. The Spondyloarthropathies (SpA) constitute a group of interrelated but heterogeneous group of disorders with common genetic and clinical characteristics. The SpA family includes Ankylosing spondylitis (AS), Reiter's syndrome/Reactive arthritis (ReA), Psoriatic arthritis (PsA), Arthritis associated with inflammatory bowel disease (IBD), and undifferentiated spondyloarthropathy. ${ }^{1}$

Enthesitis often receives scant attention in clinical and radiological evaluation and consequently treatment in musculoskeletal disorders and hence is unrecognized and under reported. We herewith present a study of enthesitis in spondyloarthritis. The anatomy of peripheral entheses has been well discussed by Benjamin.2 There are basically two major types of entheses:

1. Fibrous and

2. Fibrocartilaginous type. 
The fibrous type of enthesis is characterized by pure dense fibrous connective tissue that attaches the tendon or ligament to the bone, whereas the fibrocartilaginous type is characterized by a transitional zone of fibrocartilage (FC) at the bony interface. Fibrous entheses are typical of the metaphysis and diaphysis of long bones, but most entheses are fibrocartilaginous - for example, the sites of tendon insertions into the epiphyses of long bones. FC is most typical of tendons and ligaments where the angle of attachment changes throughout the range of joint movement. The site at which synovial joint capsules insert into the bone can also be regarded as an enthesis containing FC. Entheseal structures most commonly affected in Spondyloarthropathy are:
a) Achilles tendon.
b) Fascia plantaris.
c) Pes anserinus.
d) Trochanter major.
e) Ischial tuberosities.
f) Iliac crest.
g) Epicondylus humeri lateralis.

The radiographic features include three pathologic processes, namely inflammation, bony repair and ossification occurring consecutively or simultaneously. Typical target sites at which these processes take place are the synovial joints, discovertebral joints, apophyseal, costovertebral and costotransverse ligaments. The earliest, most consistent and most characteristic findings are seen in the sacroiliac joints. Radiographic sacroiliitis is by no means an early or obligate manifestation of the disease and may become manifest only after appropriate follow-up. ${ }^{3-6}$ There is a paucity of study of enthesitis in India; hence this study was envisaged to attempt to study the profile of entheseal involvement in patients with spondyloarthropathy.

MATERIALS AND METHODS: This descriptive observational study was conducted in a large tertiary care hospital over 20 months after obtaining institutional ethical committee approval for the study. A total of 54 consecutive patients attending the Rheumatology outpatient department were included. Persons less than 16 yrs. were excluded as they comprise of juvenile idiopathic arthritis.

Persons above 60yrs were also excluded to rule out degenerative enthesitis which would confound the results. Patients were diagnosed as Spondyloarthropathy according to European Spondyloarthropathy Study Group (ESSG) criteria. ${ }^{7}$ Detailed history, careful clinical examination and investigations including haemogram, biochemical parameters, inflammatory markers, HLA-B27, conventional radiography of sacroiliac joints, MRI imaging of the SI joints and Nuclear scintigraphy of the SI joints and the peripheral joints were carried out on each of the subjects.

Since the sacroiliac joint involves a number of ligaments and therefore the entheses we have included sacroiliac joint as an extension of enthesitis though in true sense it could be considered as a joint. Schober's test ${ }^{8}$ to assess the Lumbar spina 1 mobility, Occiput-wall distance to assess the cervical spinal mobility and Finger-floor distance to assess the Thoraco- Lumbar spinal mobility was done in each of the patients.

Any value less than $5 \mathrm{~cm}$ was taken as positive Schober's test. To assess the Costo-vertebral joints and Thoracic spine, chest expansion was measured at the level of 4th intercostal space horizontally in males and just below the breast level in females, and values less than $5 \mathrm{~cm}$ taken as 
reduced chest expansion. To elicit pain at the SI joints, Flexion-Abduction-External Rotation (FABER) test, Distraction test and Gaenslen's test were carried out.

Enthesitis was assessed by eliciting tenderness at the points of tendon insertion like greater trochanter, Achilles tendon, plantar fascia, costo-sternal joint, iliac crest and anterior superior iliac spine. Joint involvement in the form of swelling, pain and tenderness with restriction of range of motion in passive movements was clinically elicited. C-reactive protein (CRP) was done using ELISA method with ANTHOS 2010 ELISA plate reader.

HLA-B27 was done by polymerase chain reaction Conventional radiography of the sacroiliac joints was done in short axis postero-anterior prone (SAPA) view for better visualization of the joint. Plain radiographs were done for the relevant enthesis. The Radiographs were interpreted by different radiologists, by which chances of observer bias was minimized. Patients were also subjected to MRI and nuclear scintigraphy studies of the SI joints.

All the three modalities i.e.: Conventional plain radiography, MR I and Radionuclide scintigraphy of sacroiliac joints were done in 44 out of 54 patients. So the statistical analysis was done only for these 44 patients when all the three modalities were involved. As the interobserver agreement and specificity of nuclear scintigraphy is poor the same was excluded from final analysis to exclude bias arising in the study.

OBSERVATIONS AND RESULTS: Among the 54 patients who were included in our study, the following observations were made.

AGE AND SEX DISTRIBUTION: The groups of patient studied were from diverse age groups and had varied presentations. Age of the patients ranged from $19-52$ years. $83 \%$ of the patients were in 20-40 yrs. age group and the mean age was 32.2 years. This study had 6 females and 48 males i.e.: $11 \%$ and $89 \%$ respectively.

Age and sex wise distribution is given in Figure -1 and Table -1 .

DURATION OF ILLNESS: The duration of illness at presentation varied widely ranging from less than 6 months to more than 10 years. $26 \%$ of the patients presented early in the illness i.e. less than 1 year. The distribution of duration of illness in percentage is given in Figure -2 .

ENTHESITIS AND ITS DISTRIBUTION: 48 patients (88\%) had evidence of enthesitis. The distributions of sites of enthesis were as follows: Anterior superior iliac spine 7\%, Spinous process of Thoracolumbar vertebrae 9\%, Heel 33\%, Costo-sternal joint 31\%, Greater trochanter 12\% and Ischial tuberosity $8 \%$. This is depicted in Figure -3.

COMPARISON OF RADIOGRAPHY WITH DURATION OF SYMPTOMS: The value of radiographs in detecting sacroiliitis in the early phase of the disease was assessed in this study by correlating the radiographic positivity with the duration from the onset of symptoms. As the duration of symptoms increased, the sclerosed joints with periarticular erosions were better visualized on plain radiography of the SI joint. In the first 2 years of symptoms, radiography was positive in only 3 out of 14 cases, while maximum positivity in radiography was seen from 2 to 5 years of illness. Radiography was not a sensitive modality in detecting sacroiliitis in the early period of the disease. This was statistically significant with a P value of 0.04 . This is shown in Table -2 and Figure -4 . 
COMPARISON OF MRI WITH DURATION OF SYMPTOMS: MRI was sensitive in diagnosing sacroiliitis in the initial 2 years from the onset of the symptoms. 16 out of 19 patients subjected to MRI, who had symptoms less than 2 years, were found to be positive. MRI was found to be as sensitive as conventional radiography for longer duration of illness. The increased sensitivity of MRI in the early period of illness i.e. less than 2 years was statistically significant with a $P$ value of $<0.05$. This is shown in Table -3 and Figure -5.

DISCUSSION: The study group included 54 patients from diverse age groups and from different geographic areas in India. All these patients had historical evidence of sacroiliitis in the form of Inflammatory Back Pain and were diagnosed as Spondyloarthropathy according to ESSG criteria. As alluded earlier there is a paucity of data on the study on enthesis from India and this study attempts to study the pattern of entheseal involvement in patients with spodyloarthropathy

The male to female ratio in this study is 8.2:1. (Table 1 and Figure 1). The disease expression has been considered different in males and females. Males with Ankylosing spondylitis have more often had radiological spinal changes and hip involvement than their female counterparts. The difference found in our study could be attributed to the slow evolution of the disease in females and hence a delay in the diagnosis of this condition. This feature is prevalent world over and is similar to earlier Indian study by Uppal et al in $1995 .{ }^{9}$

The spectrum of Spondyloarthropathy consists of Primary Ankylosing spondylitis, Reiter's syndrome/ reactive arthritis, Psoriatic arthropathy and arthropathy associated with Inflammatory Bowel Disease.10 One of the pathologic hallmark of the disease being entheseal involvement with insertional tendonitis at different locations, it was pertinent to study the distribution of the involved enthesis in our study. The distribution of enthesitis in our study showed a maximum incidence of heel and costo-sternal joint. The other enthesis involved were greater trochanter, anterior superior iliac spine and ischial tuberosity. The study by Ball in 1987 revealed a similar pattern of involvement of enthesis in Spondyloarthropathy. ${ }^{11}$

MRI was compared against Plain radiography of Sacroiliac joints for detecting sacroiliitis changes. MRI was found to be better as compared to Plain radiography in detecting early sacroiliitis with a $\mathrm{P}$ value $<0.05$. This finding is in concordance with similar studies comparing the two modalities. Magnetic Resonance imaging was superior to plain film radiographs in visualising erosions. Radiography cannot reveal the cartilage changes and bone marrow edema, which can only be seen in MR images. In the absence of radiographic changes, MR imaging can provide objective and complementary findings of sacroiliitis in patients with AS. Due to the ability to image cartilage changes and bone marrow edema directly, MR imaging may be particularly useful in early diagnosis of sacroiliitis. ${ }^{12-14}$

Limitation of this study: The major limitation of the study is that the enthesis was assessed clinically and not radiographically using musculoskeletal ultrasound or specific enthesis sequence of MRI. The former was not available at our institution and the latter was not done as there was no provision for dedicated musculoskeletal MRI protocols built in. This was a clinical observational study which looked at often neglected enthesitis in spondyloarthritis. Though radiological evaluation was done for sacroiliitis, detailed radiological evaluation could not be done for enthesitis due to logistic reasons. Further studies using dedicated musculoskeletal ultrasound and musculoskeletal MRI to assess enthesitis are needed. 


\section{REFERENCES:}

1. McGonagle D, Gibbon W, Emery P. Classification of inflammatory arthritis by enthesitis. Lancet.1998; 352 (9134): 1137-40.

2. Benjamin M, Toumi H, Ralphs J R, Bydder G, Best T M, Milz S. Where tendons and ligaments meet bone: attachment sites ('entheses') in relation to exercise and/or mechanical load. J Anat. v. 208 (4); 2006. $471-490$.

3. Lévesque $\mathrm{R} Y$, Michel AE. Radiologic Findings in Adults with Seronegative Spondyloarthropathies; distinguishing the chronic arthropathies in adulthood. Can Fam Physician. 1992; 38: 2105-2106, 2109-2112, 2115-2118.

4. Braunstein EM, Martel W, Moidel R. Ankylosing spondylitis in men and women: a clinical and radiographic comparison. Radiology. 1982; 144 (1): 91-94.

5. Dihlmann W. Current radiodiagnostic concept of ankylosing spondylitis. Skeletal Radiol.1979; 4 (4): 179-188

6. Gold RH, Bassett LW, Seeger LL. The other arthritides. Roentgenologic features of osteoarthritis, erosive osteoarthritis, ankylosing spondylitis, psoriatic arthritis, Reiter's disease, multicentric reticulohistiocytosis, and progressive systemic sclerosis. Radiol Clin North Am. 1988; 26 (6): 1195-1212.

7. Ozgur A, Salih O. Classification criteria for Spondyloarthropathies. World J Orthop.2011; 2 (12): 107 - 115. ISSN 2218-5836.

8. Davis JC Jr, Gladman DD. Spinal Mobility Measures in Spondyloarthritis: Application of the OMERACT Filter. J Rheumatol. 2007 Apr; 34 (4): 666-70

9. Uppal SS, Pande I, Singh G, Kailash S, Kakker R, Kumar A, Mehra NK, Giri TK, Sekharan NG, Malaviya AN. Profile of HLA-B27-related 'unclassifiable' seronegative spondyloarthropathy in females and its comparison with the profile in males. Br J Rheumatol. 1995; 34 (2): 137-40.

10. Dougados M, van der Linden S, Juhlin R, et al. The European Spondylarthropathy Study Group preliminary criteria for the classification of spondylarthropathy. Arthritis Rheum. 1991; 34 (10): 1218-27.

11. Ball J. Enthesopathy of rheumatoid and ankylosing spondylitis. Ann Rheum Dis. 1971; 30(3): 213-223.

12. Vinson EN, Major NM. MR imaging of ankylosing spondylitis. Semin Musculoskelet Radiol. 2003; 7(2): 103-13.

13. Geijer M, Gothlin GG, Gothlin JH. The clinical utility of computed tomography compared to conventional radiography in diagnosing sacroiliitis. A retrospective study on 910 patients and literature review. J Rheumatol. 2007; 34 (7):1561-5.

14. Brandt J, Bollow M, Häberle J, Rudwaleit M, Eggens U, Distler A, Sieper J, Braun J. Studying patients with inflammatory back pain and arthritis of the lower limbs clinically and by magnetic resonance imaging: many, but not all patients with sacroiliitis have spondyloarthropathy. Rheumatology (Oxford) 1999; 38 (9): 831-836. 
ORIGINAL ARTICLE

\begin{tabular}{|c|c|c|c|}
\hline Age groups & Male No: & Female No. & Total No. \\
\hline 10-19 yrs. & 1 & 0 & 1 \\
\hline 20-29 yrs. & 20 & 2 & 22 \\
\hline $30-39$ yrs. & 20 & 3 & 23 \\
\hline $40-49$ yrs. & 6 & 0 & 6 \\
\hline 50-59 yrs. & 1 & 1 & 2 \\
\hline TOTAL & $\mathbf{4 8}$ & $\mathbf{6}$ & $\mathbf{5 4}$ \\
\hline \multicolumn{4}{|c}{ Table 1: Age and sex wise distribution } \\
\hline
\end{tabular}

\begin{tabular}{|c|c|c|}
\hline Duration in Years & Radiograph Positive & Radiograph Negative \\
\hline $0-1 \mathrm{yr}$ & 2 & 8 \\
\hline $1-2 \mathrm{yr}$ & 1 & 3 \\
\hline $2-3 \mathrm{yr}$ & 5 & 0 \\
\hline $3-4 \mathrm{yr}$ & 5 & 3 \\
\hline $4-5 \mathrm{yr}$ & 5 & 1 \\
\hline $5-6 y r$ & 5 & 0 \\
\hline $6-7 y r$ & 2 & 2 \\
\hline $7-8 y \mathrm{r}$ & 3 & 3 \\
\hline $8-9 y r$ & 3 & 0 \\
\hline $9-10 \mathrm{yr}$ & 3 & 0 \\
\hline Total & $\mathbf{3 4}$ & $\mathbf{2 0}$ \\
\hline
\end{tabular}

Table 2: Comparison of Radiograph and duration of symptoms

$\mathrm{P}$ value $=0.04$

\begin{tabular}{|c|c|c|}
\hline Duration in years & MRI positive & MRI negative \\
\hline $0-1$ & 11 & 3 \\
\hline $1-2$ & 5 & 0 \\
\hline $2-3$ & 4 & 2 \\
\hline $3-4$ & 6 & 0 \\
\hline $4-5$ & 3 & 0 \\
\hline $5-6$ & 2 & 1 \\
\hline $6-7$ & 2 & 3 \\
\hline $7-8$ & 2 & 2 \\
\hline $8-9$ & 1 & 1 \\
\hline Total & $\mathbf{3 6}$ & $\mathbf{1 2}$ \\
\hline
\end{tabular}

Table 3: Comparison of MRI with duration of symptoms

$\mathrm{P}$ value $=<0.05$ 

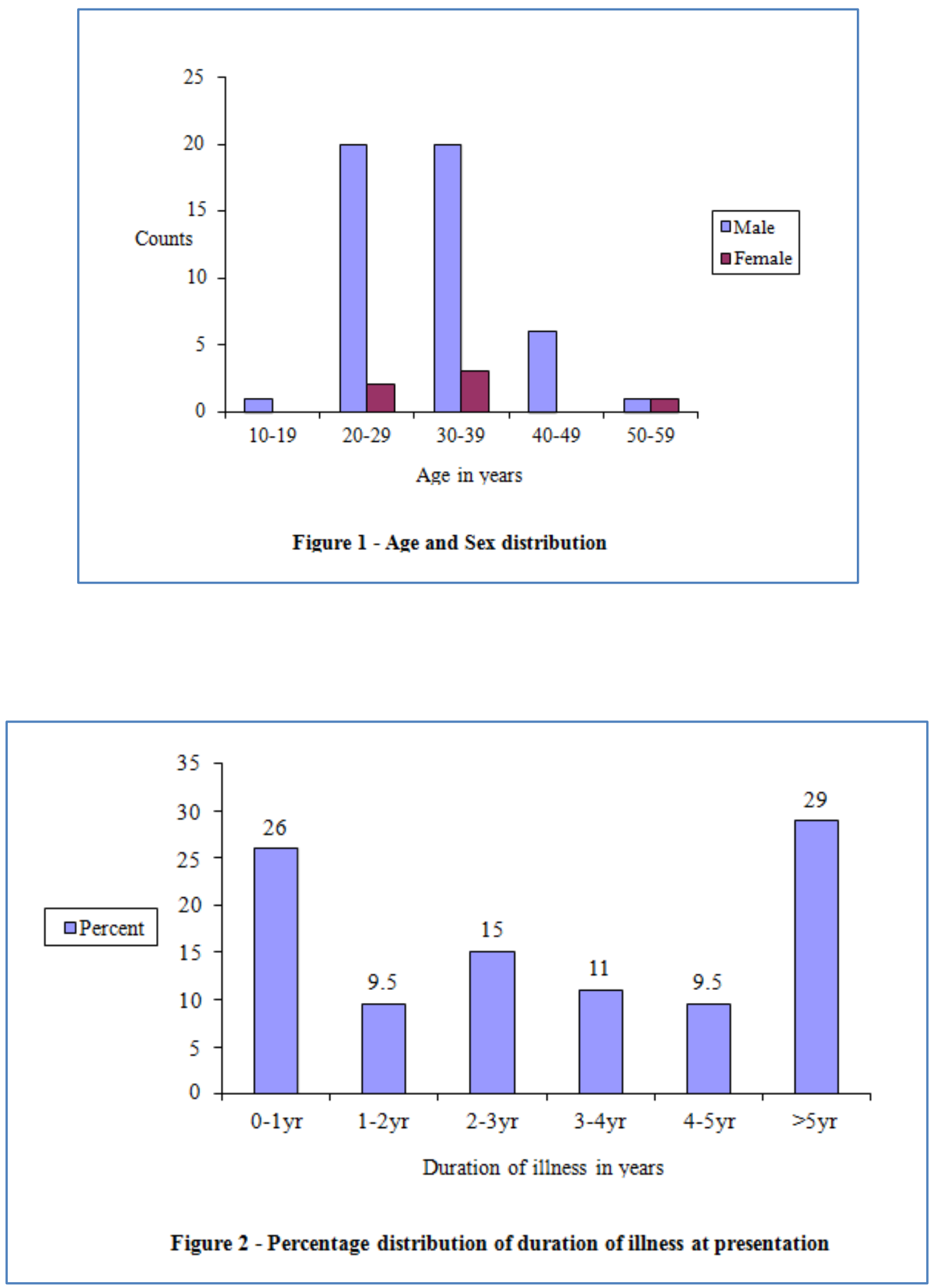

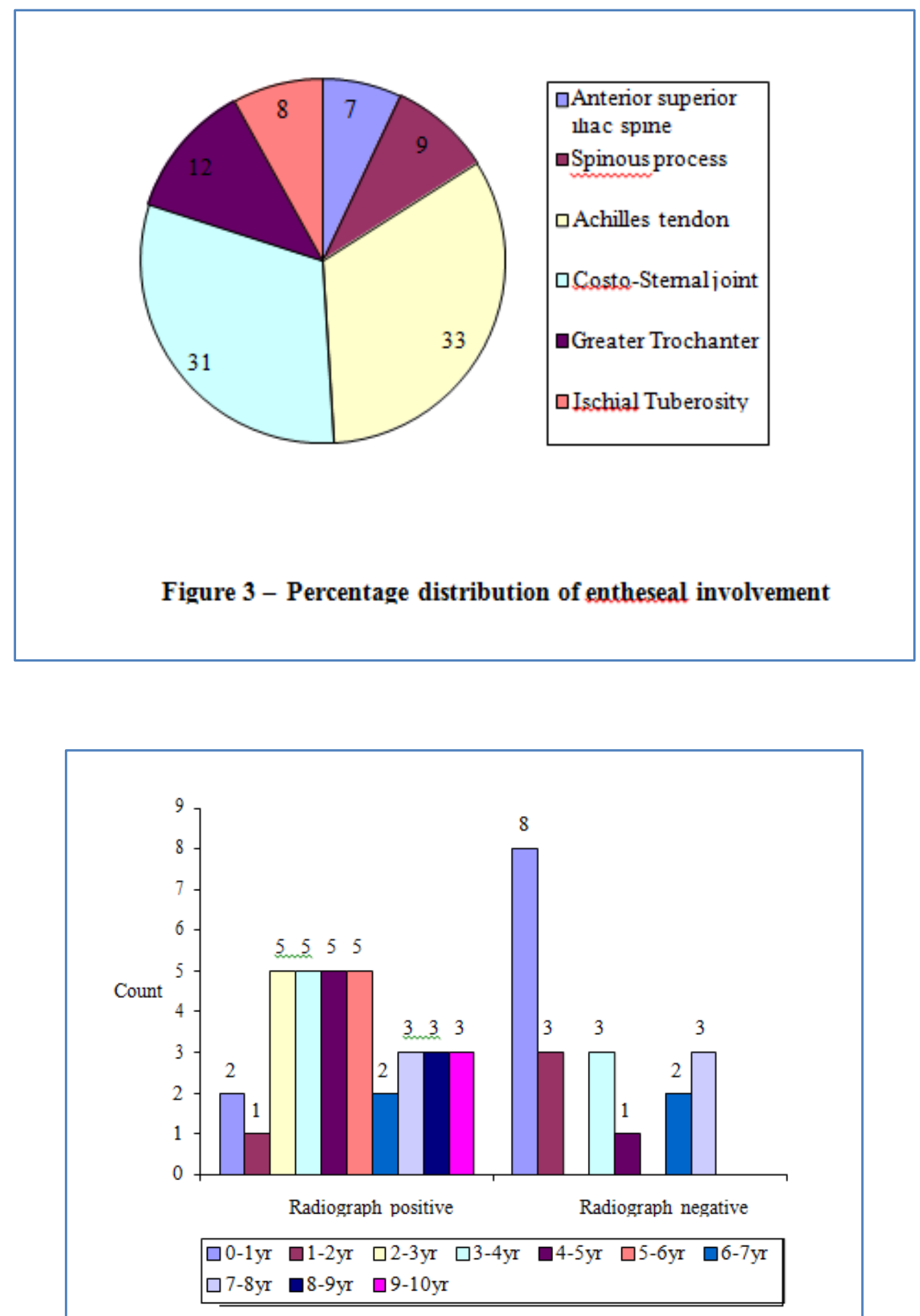

Figure 4 - Comparison of Radiograph with duration of symptoms 


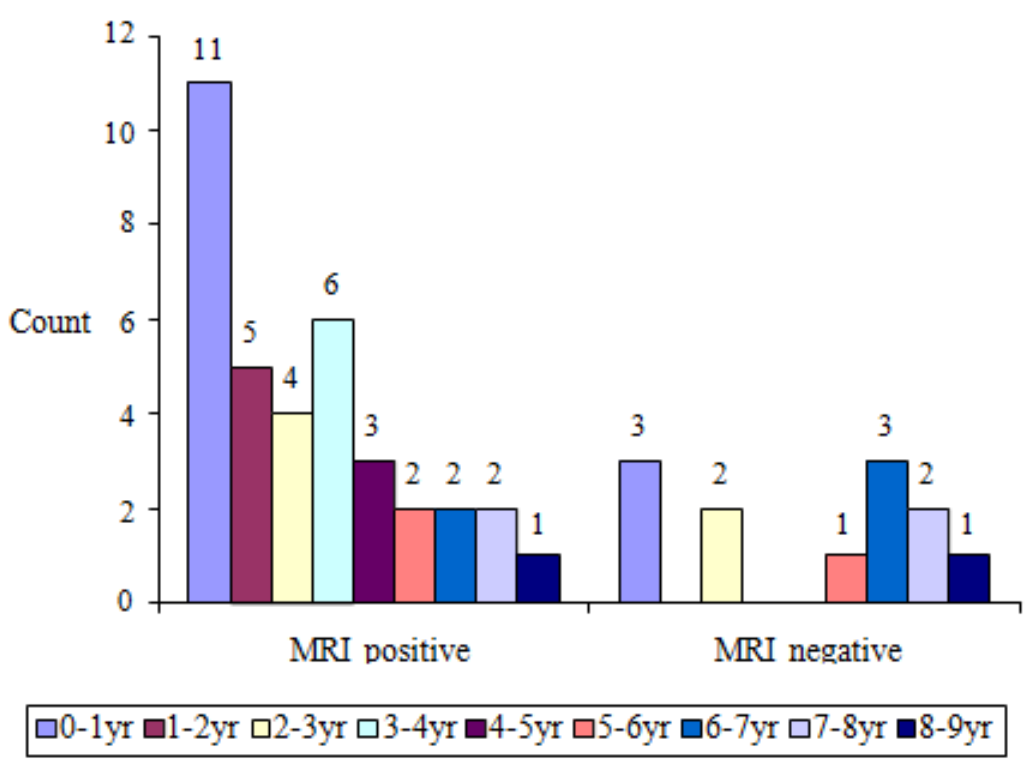

Figure 5-Comparison of MRI with duration of symptoms

\section{AUTHORS:}

1. Surajit Ghatak

2. K. Shanmuganandan

\section{PARTICULARS OF CONTRIBUTORS:}

1. Professor and HOD, Department of Anatomy, All India Institute of Medical Sciences, Jodhpur.

2. Professor, Department of Rheumatology, Army Hospital Research \& Referral, New Delhi.
NAME ADDRESS EMAIL ID OF THE CORRESPONDING AUTHOR:

Dr. Surajit Ghatak,

Professor and HOD,

Department of Anatomy, All India Institute of Medical Sciences, Jodhpur.

Email: surajit_ghatak@rediffmail.com

Date of Submission: 26/06/2014.

Date of Peer Review: 27/06/2014.

Date of Acceptance: 07/07/2014.

Date of Publishing: 12/07/2014. 